ORIGINAL ARTICLE

\title{
Dietary Diversity, Nutritional status and Academic performance of pupils in public primary schools in Port Harcourt Metropolis
}

Uzosike TCJ ${ }^{1}$, Okeafor $I^{2}$, Mezie-Okoye $M^{3}$

1Department of Community Medicine, Rivers State University, Nkpolu, Port Harcourt, Rivers State, Nigeria

2Eagles Watch Research Centre and Care, Rumuigbo, Port Harcourt, Rivers State, Nigeria

${ }^{3}$ Department of Community Medicine, University of Port Harcourt Teaching Hospital, Choba, Port

Harcourt, Rivers State, Nigeria

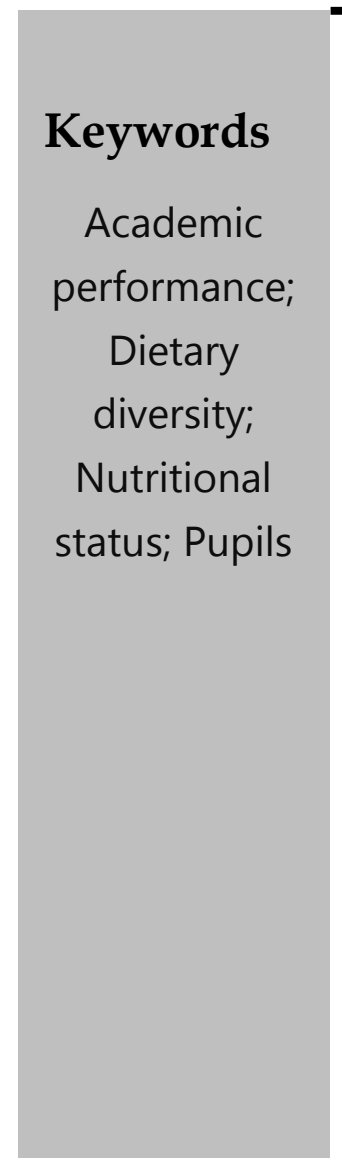

\section{INTRODUCTION}

Globally, Dietary Diversity (DD) has been identified as a vital element for high-quality

\section{ABSTRACT} academic performance.
Background: Poor nutrition can hinder pupils from achieving good educational performance at school. This study provides information on the dietary diversity and nutritional status of school-age children in Rivers State, and their relationship with

Methods: A descriptive cross-sectional study design was conducted among pupils attending public primary schools, aged 6-11 years. Using a multi-stage sampling technique, data on dietary diversity was collected using a two-day 24-hour dietary recall tool adapted from the Food and Agriculture Organization (FAO) guidelines for measuring household and individual dietary diversity. Nutritional status was assessed using anthropometric measures and educational performance was assessed using the end of term examination results for Mathematics and English language in the selected schools. Statistical analyses were performed at $\mathrm{p}$ level of 0.05 .

Results: The study had a total of 847 public primary school pupils, comprising of 441 (52.1\%) males and 406 (47.9\%) females The minimum and maximum dietary diversity score (DDS) obtained from the pupils were one and five, respectively with a mean DDS of $3.67 \pm 0.71$. The frequency of stunting, underweight and overweight among the pupils were $39.4 \%, 23.0 \%$ and $6.0 \%$ respectively. Dietary diversity was significantly associated with academic performance $(\mathrm{p}=0.001)$, with higher odds of poor academic performance in both English language and Mathematics reported among pupils with low DDS in comparison to those with normal DDS.

Conclusion: Dietary diversity for primary school pupils should be promoted to achieve optimal academic performance amidst other benefits.

Correspondence to: Dr Tondor Cleopatra Jumbo Uzosike Department of Community Medicine, Rivers State University, Port Harcourt, Rivers State, Nigeria Email: tondorj@yahoo.com Telephone: +2348057002837

diets. ${ }^{1}$ DD is a measure of the number of individual foods or food groups consumed in a given reference period. ${ }^{2}$ Dietary diversity is related to the pillars of food security 
(accessibility, availability and utilization). ${ }^{3}$ It can reflect household access to a variety of foods and can also act as a proxy for individual nutrient adequacy. ${ }^{4,5}$ Poor dietary intakes such as monotonous diets are related to increased risk of malnutrition and other diseases and therefore local and international dietary guidelines have suggested an improvement on the variety of foods consumed by individuals and families. ${ }^{3}$ For growing children who are at risk of being malnourished, they need more energy and nutrient-dense foods to grow and develop both physically and mentally and to live a healthy life. Therefore, consumption of a wide variety of food items and food groups can improve the nutritional adequacy of their diet. ${ }^{6}$

Nutrition is the ingestion of food, considered in relation to the body's dietary needs and implies an adequate, well-balanced diet combined with regular physical activity. ${ }^{7}$ Therefore, children who are well-nourished with balanced diets are more likely to be healthy, productive and able to learn. ${ }^{8}$ They attain better academic performance, develop to adults in a good state of health and consequently give their children a healthier beginning in life. 9 On the other hand, malnutrition is a pathological condition resulting from abnormal nutrition. It is broadly classified as under-nutrition, as a result of inadequate consumption of energy and other nutrients, and over-nutrition occurring as a result of excess intake of energy giving foods and other nutrients essential for survival, growth, reproduction and capacity to learn and function in society. ${ }^{10}$ Malnutrition has been described as a significant public health problem in most developing countries and has affected more than $30 \%$ of children below the age of five years. ${ }^{11}$ This may be the reason why most available studies done have focused on children below the age of five. ${ }^{12,13}$ However, problems with nutrition in children below the age of five may progress as they attain the primary school age if early corrective intervention or measures are not done and this may lead to harmful effects on the child's health and school performance. ${ }^{14}$

Globally, malnutrition among school-age children is becoming a major public health concern. More than 200 million school-age children are stunted and underweight. ${ }^{15}$ If appropriate measures are not taken and at this rate, approximately one billion school children will be growing up by 2020 with impaired physical and mental development. 16-18 The poor nutritional status of children in primary schools, therefore, impacts their health, cognition, and subsequently their educational achievement.19,20 Noteworthy, diets of school children in developing countries are restricted in diversity (variety of food group consumption in a meal), with a minimum intake of animal foods and fruits and vegetables and increased intake of highly refined foods. ${ }^{21}$ As a result, many children are deficient in micronutrients and this can have negative consequences for the attainment of good health and achievement of educational objectives. Malnutrition combined with a heavy disease burden especially among the school-age children (611 years) could lead to high drop-out rates 
and poor learning achievement scores. Hence, this study aimed to assess the dietary diversity, nutritional status and academic performance of children in public primary schools. It further explored the relationship between nutritional status and academic performance as a tool to provide empirical evidence for the promotion of optimal nutrition among primary school pupils.

\section{METHODOLOGY}

The study was conducted in Port Harcourt metropolis, the capital of Rivers State, Nigeria. The metropolis is the major commercial city of the state and comprises Port Harcourt Local Government Area (PHALGA) and Obio-Akpor Local Government Area (LGA) both of which are part of the twenty-three Local Government Areas of Rivers State. Port Harcourt LGA has 41 government/public primary schools and Obio-Akpor LGA has 52 government/public primary schools. ${ }^{22} \mathrm{~A}$ school-based cross-sectional study design involving primary school children between the ages of 6 and 11 years. Children with a medical condition that could affect their nutritional status such as sickle cell disease were excluded from the study. The sample size was calculated using the formula for cross-sectional studies. ${ }^{23}$

$n=\frac{(z)^{2} p(1-p)}{e^{2}}$

Using a standard normal deviate corresponding to the required significant level of $5 \%$ (denoted as $z$ ), the underweight prevalence of $46.4 \%$ from a similar study involving primary school pupils, ${ }^{24}$ level of precision (denoted as $e$ ) of $5 \%$, an estimated non-response of $10 \%$ and a design effect of 2, a sample size of 847 was obtained for the study.

A multi-stage sampling technique was used to select pupils from public schools in Port Harcourt metropolis. In the first stage, one LGA was selected from the two LGAs making up Port Harcourt Metropolis, through simple random sampling. In the second stage, simple random sampling was used to select six schools from the sampling frame comprising of the list of schools in the selected LGA. In the third stage, participants were selected by simple random sampling using a table of random numbers, and the sampling frame included all pupils in the selected school from primary one to six. However, the number of pupils selected from each school for this study was calculated by proportionate to size allocation, based on the number of pupils in each selected school.

Data on dietary diversity and dietary pattern were obtained using a 24-hour dietary recall on two non-consecutive days (three days apart). Participants were asked to recall all foods eaten and beverages taken in the previous twenty-four hours prior to the interview. A scale of nine food groups was used in assessing the individual dietary diversity of subjects. ${ }^{25}$ The food groups include; starchy staples, dark green leafy vegetables, vitamin A-rich fruits (e.g. sweet potatoes) and vegetables, other fruits and 
vegetables, organ meat, meat and fish, eggs, legumes, nuts and seeds, milk and milk products. Using information collected from the 24-hour dietary recall, the foods eaten by participants were categorized into food groups and dietary diversity scores for individuals was derived using the FAO guidelines for measuring household and individual dietary diversity. ${ }^{25}$ One mark was awarded to each food group consumed over the reference period, and the sum of all points was calculated for the dietary diversity score for each individual. An average of the dietary diversity scores collected on the 2 non-consecutive days was done to obtain the final score for each participant. The minimum and maximum dietary diversity scores were one and nine, respectively. The dietary diversity scores (DDS) was described as low ( $\leq 3$ food groups consumed/day), moderate (4-5 food groups consumed/day) and high ( $\geq 6$ food groups consumed/day). The dichotomized DDS categories were low $(\leq 3$ food groups consumed/day) and normal DDS ( $>3$ food groups consumed/day). ${ }^{26}$

Nutritional status was determined by measuring weights using the seca mechanical bathroom weighing scale in kilograms (Kg) and heights using a wooden stadiometer in centimetres (cm). Subsequently, values of anthropometric indices; height-for-age $Z$-scores, weight-forage $Z$-scores, and BMI-for-age $Z$-scores obtained for each pupil were compared with $Z$-score values of 2007 WHO growth reference standards for 5-19 years ${ }^{27}$ to determine children who were stunted, underweight, overweight or obese. The WHO growth reference standards take into consideration the growth pattern of children in developing countries, hence its use in this study. Children who were $2 \mathrm{SD}$ below the reference median (i.e. a $Z$-Score of less than -2) were considered to be undernourished i.e. to be stunted (Height-for-age $Z$-score less than -2) or to be underweight (Weightfor-age $Z$-score less than -2). Children with measurements below $3 \mathrm{SD}$ (a Z-Score of less than-3) were considered to be severely undernourished. A BMI-for-age $\mathrm{Z}$-score of $>+1 \mathrm{SD}$ to $\leq+2 \mathrm{SD}$ represents overweight and $>+2 \mathrm{SD}$ represents obesity. Children with $Z$ scores of $-2 \mathrm{SD}$ to $+2 \mathrm{SD}$ were considered to be normal.

The educational performance was assessed using the first and second term examination scores in Mathematics and English language. These two subjects were chosen for assessing educational performance because they are "core subjects" in the primary school curriculum in Nigeria. Mean scores of the educational performance of the pupils was categorized and recorded as high $(\geq 75 \%)$, average $(50-74 \%)$ or low $(<50 \%)$ performance. The mean scores were further dichotomized into good $(\geq 50 \%)$ and poor $(\leq 49 \%)$.

Questionnaires were screened for completeness, coded and entered into the Statistical Package for Social Sciences (SPSS) version 21.0 software for analysis. Anthropometric indices were calculated using the WHO AnthroPlus version 1.0.4 to obtain the nutritional status of school 
children. Descriptive statistics employed means and standard deviation for numerical variables while frequencies and proportions were used for categorical variables. The dependent variable was educational performance while the independent variables were dietary diversity and nutritional status. The relationship between the independent variables and the dependent variable of this study was explored using bivariate and multivariate analyses.

The bivariate analysis employed Chi-square statistics with a p-value of less than 0.05 considered statistically significant. Statistically significant variables on bivariate analysis were entered into a multivariate analysis model to adjust for confounders. Multivariate analysis was performed using a non-step wise unconditional binary logistic regression model. Odds ratio and $95 \%$ confidence intervals were determined as measures of association. Statistical inference was set at a level of 0.05 .

Ethical clearance to conduct this research was sought and obtained from the Hospital Ethical Committee of the University of PortHarcourt Teaching Hospital (UPTH) prior to commencement of the study. Permission to carry out this was obtained from the Rivers State Ministry of Education and Head Teachers of the selected primary schools. A consent form and information sheet was sent out to the parents of selected pupils to enable them understand the purpose, procedures, the potential risks and benefits of their child/wards involvement, and their willingness to participate in the study. No financial obligation to the parents of participating pupils was required. Assent was sought from each pupil and they were informed that refusal to participate in the study or withdrawal did not attract any penalty. All data was kept secure and made available only to the researcher. Confidentiality and privacy was respected during the course of the research. Nutrition education on healthy feeding practices was rendered to all pupils of the schools after measurements were taken. Parents of children found to be sick or malnourished were informed and referred to the nearest health facility for treatment and follow-up.

\section{RESULTS}

This study had a total of 847 public primary school pupils aged 6 years to 11 years. The mean age of the pupils was $8.60 \pm 1.68$ years. There were $441(52.1 \%)$ males and $406(47.9 \%)$ females in the study. A total of $561(66.2 \%)$ mothers of the pupils achieved up to secondary education and 286 (33.8\%) had achieved tertiary education. There were $631(74.5 \%)$ mothers engaged in paid employment while $216(25.5 \%)$ of the mothers were not employed. (Table 1) Starchy staples had the highest frequency of consumption, as all the 847 pupils (100\%) consumed this food group within the 24hours dietary recall. The less frequently consumed food groups were Vitamin A-rich fruits and vegetables 147 (17.1\%), other fruits and vegetables $65(7.7 \%)$, and organ meat $99(11.7 \%)$. Less than half of the pupils 
consumed milk and milk products 376 (44.4\%). (Table 2)

The minimum and maximum dietary diversity score (DDS) obtained from the pupils were one and five respectively with a mean DDS of $3.67 \pm 0.71$. Low DDS was noted in 390 (46.0\%) of the pupils, moderate DDS in 457 (54.0\%) and none of the pupils $(0.0 \%)$ had high DDS. The mean weight-forage $Z$-score was $-0.72 \pm 1.04$; the mean height-for-age $Z$-score was $-1.24 \pm 0.86$ while the mean BMI-for-age $Z$-score was $0.10 \pm 0.98$. The frequencies of stunting, underweight and overweight among the pupils were 334 (39.4\%), 162 (23.0\%) and $51(6.0 \%)$, respectively while $462(54.5 \%)$ of the pupils had normal nutritional status (Figure 1).

\begin{tabular}{lcc}
\multicolumn{3}{l}{ Table 1: Sociodemographic characteristics } \\
\hline Variable & Frequency & Percent \\
\hline $\begin{array}{l}\text { Age (years) } \\
\text { Mean } \pm \text { SD }\end{array}$ & $8.60 \pm 1.68$ & \\
& & \\
Sex & & \\
Male & 441 & 52.1 \\
Female & 406 & 47.9 \\
Mother's highest & & \\
educational level & & \\
$\begin{array}{l}\text { Secondary or less } \\
\text { Tertiary }\end{array}$ & 561 & 66.2 \\
& 286 & 33.8 \\
$\begin{array}{l}\text { Mother's } \\
\text { employment }\end{array}$ & & \\
status & & \\
Not Employed & 216 & 25.5 \\
Employed & 531 & 74.5 \\
& & \\
\end{tabular}

The educational performance of the pupils showed that in English Language, less than one-quarter of the pupils had high scores $183(21.6 \%)$, while the highest proportion of them had average scores 559 (66.0\%). Concerning Mathematics, slightly above one-tenth of the pupils had high scores 125 $(14.8 \%)$, while half of them had average scores 428 (50.5\%). Table 3.

Table 4 shows that a higher proportion of pupils whose mothers had secondary education or a lower level of education performed poorly in both English language (15\% vs 7.3\%; $\mathrm{p}=0.001$ ) and Mathematics (44.2\% vs $16.1 \%, \mathrm{p}=0.001)$ compared to pupils whose mothers' had tertiary education. Similarly, a higher proportion of pupils whose mothers were not employed performed poorly at school for both English language $(18.5 \%$ vs $10.3 \%)$ and Mathematics (44.9\% vs $31.2 \%$ ), compared to pupils whose mothers' were employed, and the findings were statistically significant at $\mathrm{p}=0.002$ and $\mathrm{p}=0.001$ respectively. $\mathrm{A}$ significant relationship between DDS and academic performance for both English language and Mathematics at $p=0.001$ respectively. A higher proportion of pupils with low DDS had poor academic performance in English language and Mathematics in comparison to those with high DDS, (23.8\% vs $2.6 \%)$ and $(74.6 \%$ vs $0.7 \%)$, respectively.

Regarding nutritional status, a higher proportion of pupils who were stunted and underweight performed poorly in English language [(24\% vs $4.9 \%),(24.1 \%$ vs $7 \%)]$ and Mathematics [(73.1\% vs $9.7 \%),(74.1 \%$ vs $24.0 \%)$ compared to pupils with a normal nutritional status and these findings were 
Table 2: Food groups consumed by pupils

\begin{tabular}{lll}
\hline Food group* & Frequency (n=847) & Percent \\
\hline Starchy staples & 847 & 100.0 \\
Legumes & 526 & 62.1 \\
Flesh meats and fish & 386 & 45.6 \\
Milk and milk products & 376 & 44.4 \\
Dark green leafy vegetables & 347 & 41.0 \\
Eggs, & 328 & 38.7 \\
Vitamin A rich fruits and vegetables & 145 & 17.1 \\
Organ meat & 99 & 11.7 \\
Other fruits and vegetables & 65 & 7.7 \\
\hline
\end{tabular}

*Multiple responses applied

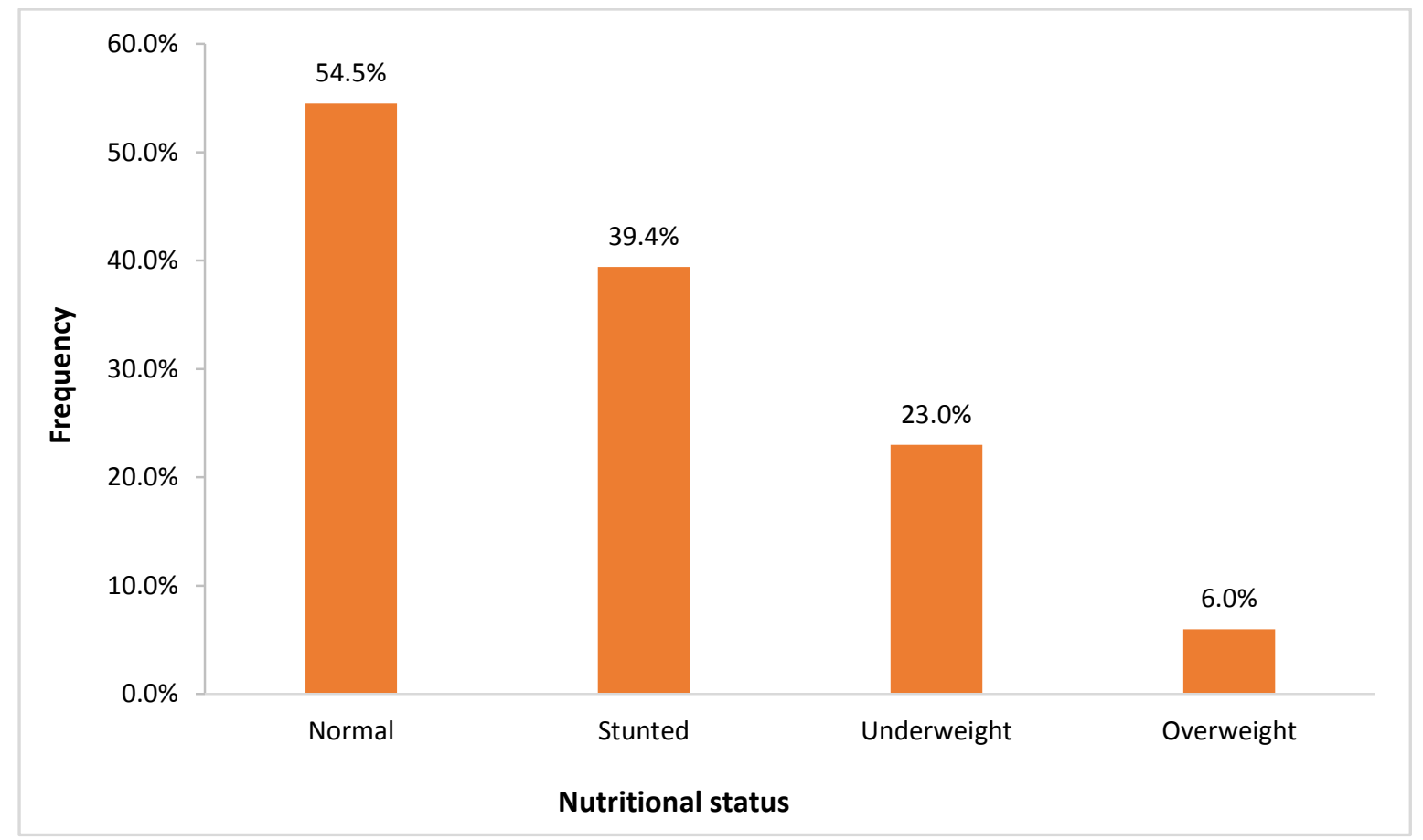

Figure 1: Nutritional status of pupils in the study

Table 3: Educational performance score of pupils in the study

\begin{tabular}{lll}
\hline Educational performance score & Frequency (n=847) & Percent \\
\hline English Language & & \\
High & 183 & 21.6 \\
Average & 559 & 66.0 \\
Low & 105 & 12.4 \\
Mathematics & & \\
High & 125 & 14.8 \\
Average & 428 & 50.5 \\
Low & 294 & 34.7 \\
\hline
\end{tabular}

significant at $\mathrm{p}=0.001$ for all the have normal nutritional status performed observations, respectively. While a higher poorly in both English language $(13.1 \%$ vs proportion of pupils who were observed to $2.0 \%)$ and Mathematics $(36.3 \%$ vs $9.8 \%)$ 
compared to the proportion of overweight pupils and this observation was significant $p=0.001$ respectively. The multivariate analysis using the logistic regression model showed that mothers employment status, dietary diversity, HAZ-for-age and WAZ-forage $Z$-score were predictors of academic performance in English. Pupils whose mothers were not employed were more likely to perform poorly in English language (Adjusted odds ratio: 1.969; 95\% CI - 1.234, 3.165). Pupils with low DDS were also more likely to have poor academic performance in English than those with high DDS (Adjusted odds ratio-7.042; 95\% CI -2.985, 62.50). Pupils with stunting were also more likely to have poor academic performance compared to pupils with normal nutritional status (Adjusted odds ratio-2.096; 95\% CI - 1.066, 4.132). Underweight pupils were about 2 times more likely to have poor academic performance in English than those not underweight (Adjusted odds ratio-2.014; 95\% CI - 1.076, 3.771).

For academic performance in Mathematics, mothers' employment status, dietary diversity and BMI-for-age $Z$-scores were the significant predictors. Pupils whose mothers' were not employed were more likely to have poor academic performance in English language (Adjusted odds ratio$2.532 ; 95 \%$ CI $-1.425,4.505)$, compared to pupils whose mothers were not employed. Pupils with low DDS were more likely to have poor academic performance in Mathematics than those with high DDS (Adjusted odds ratio-47.72; 95\% CI - 31.75, 125.00) while pupils who were overweight were more likely to have poor academic performance in Mathematics in comparison to those with normal nutritional status (Adjusted odds ratio- 0.172; 95\% CI - 0.052, 0.567) as shown in Table 5.

\section{DISCUSSION}

The finding that all pupils in this schoolbased study carried out in public primary schools in Port Harcourt metropolis consumed starchy staples over the two-day 24-hour recall period is however not surprising as this food group tops the list of staple foods in Nigeria and West Africa. The observation that more than forty percent of the pupils in index study consumed dark green leafy vegetables, flesh meats and fish, legumes, milk and milk products is similar to the observations made by researchers in Ghana $^{28}$ and a researcher in south-western Nigeria. ${ }^{29}$ Noteworthy, the low proportion noted in the consumption of organ meat, eggs, fruits and vegetables and other vitamin A rich fruits among the pupils is worrisome as these food groups are essential for their optimal growth and food digestion. This may be due to the maternal employment status of the mothers where about a third of them were not employed and may not be able to afford a variety of meals. Nonetheless, this finding possibly uncovers the need to include consumption of these food groups as part of the nutrition education in the school nutrition curriculum as well as encouraging schools to practice fruit consumption by creating fruit days in the primary schools. ${ }^{30}$ 
Concerning the dietary diversity pattern, the mean value noted in this study is similar to values observed by Girma et al ${ }^{31}$ in Ethiopia who also used the FAO individual dietary diversity score indicator as was used in this study.

However, studies conducted by Owusu et $\mathrm{al}^{28}$ and Olumakaiye ${ }^{29}$ showed higher mean values than that of the present study. Although the study by Owusu et al employed the FAO individual dietary diversity food group, which was similarly used in the present study, these researchers recorded both foods provided by the school feeding program and foods eaten at home, thus increasing the variety of foods consumed in a day. The use of FANTA household dietary diversity score indicator by Olumakaiye, which contains sixteen food groups to assess dietary diversity, and hence giving the participants better chance of having a high dietary diversity score could be the reason for the higher mean value than the index study. A recommendation that the Nigerian government needs to not only strengthen the agricultural sector but also institute measures and avenues for financial empowerment of its citizenry will not only alleviate food insecurity but will enable parents to provide the adequate diet needed to achieve good nutritional status and improve in their academic performance.

The prevalence of stunting reported in the present study is remarkably higher than reports stated by other researchers in Nigeria, ${ }^{32,33}$ Kenya $^{34}$ and India, ${ }^{35}$ although the National Centre for Health Statistics
(NCHS) was used as reference standards for these studies as against the WHO reference standard that was used in the present study. This implies that stunting which indicates past or chronic malnutrition is still very much prevalent among pupils in public schools. Also, these survivors of poor nutrition in the past may be suffering from other consequences of chronic malnutrition such as poor cognitive development. Although some other studies ${ }^{36,37}$ have reported higher rates of stunting among pupils in comparison to index study, the need for optimal nutrition cannot be overemphasized as the benefits always outweigh the cost.

Concerning the occurrence of underweight among pupils in this study, the prevalence of underweight reported in the present study was much lower than values reported by Adegun et $\mathrm{al}^{38}$ in Ekiti, Nigeria, Olanipekun et $\mathrm{al}^{39}$ in Ibadan, Nigeria, Agbo et $\mathrm{al}^{24}$ in Jos, Nigeria, which were similarly carried out in public primary schools. However, Olatona and collaeagues ${ }^{40}$ in their study carried out in public primary schools in Lagos reported a lower prevalence of underweight of $6.8 \%$ in comparison to the $23.0 \%$ reported in index study. The dissimilarities in findings could be attributed to the differences in socioeconomic status, industrialization and urban development in these states. The occurrence of underweight and overweight among the pupils in present study subtly exposes a double burden of malnutrition 


\begin{tabular}{|c|c|c|c|c|}
\hline \multirow[b]{3}{*}{ Variables } & \multicolumn{2}{|c|}{ Academic Performance } & \multirow{2}{*}{\multicolumn{2}{|c|}{ Mathematics }} \\
\hline & \multicolumn{2}{|c|}{ English } & & \\
\hline & $\begin{array}{l}\text { Poor } \\
\text { n (\%) }\end{array}$ & $\begin{array}{l}\text { Good } \\
\text { n (\%) }\end{array}$ & $\begin{array}{l}\text { Poor } \\
\text { n (\%) }\end{array}$ & $\begin{array}{l}\text { Good } \\
\text { n (\%) }\end{array}$ \\
\hline \multicolumn{5}{|l|}{ Age (years) } \\
\hline $6-8$ & $41(10.2)$ & 361 (89.8) & 159 (39.6) & $243(60.4)$ \\
\hline \multirow[t]{2}{*}{$9-11$} & $64(14.4)$ & 381 (85.6) & $135(30.3)$ & $310(69.7)$ \\
\hline & \multicolumn{2}{|c|}{$\chi^{2}=3.403 ; p=0.040^{*}$} & \multicolumn{2}{|c|}{$\chi^{2}=7.914 ; p=0.003^{*}$} \\
\hline \multicolumn{5}{|c|}{ 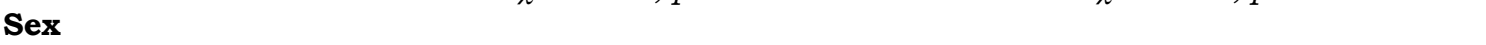 } \\
\hline Female & $49(12.1)$ & 357 (87.9) & $155(38.2)$ & $251(61.8)$ \\
\hline \multirow[t]{2}{*}{ Male } & $56(12.7)$ & $385(87.3)$ & $139(31.5)$ & $302(68.5)$ \\
\hline & \multicolumn{2}{|c|}{$\chi^{2}=0.077 ; p=0.432$} & \multicolumn{2}{|c|}{$\chi^{2}=4.135 ; p=0.025^{*}$} \\
\hline \multicolumn{5}{|l|}{ Mother's Educational Level } \\
\hline Secondary education or less & $84(15.0)$ & $477(85.0)$ & $248(44.2)$ & $313(55.8)$ \\
\hline \multirow[t]{2}{*}{ Above secondary education } & $21 \quad(7.3)$ & 265 (92.7) & $46(16.1)$ & $240(83.9)$ \\
\hline & \multicolumn{2}{|c|}{$\chi^{2}=10.156 ; p=0.001^{*}$} & \multicolumn{2}{|c|}{$\chi^{2}=66.109 ; p=0.001 *$} \\
\hline \multicolumn{5}{|l|}{ Mother's Employment status } \\
\hline Not employed & $40(18.5)$ & $176(81.5)$ & $97(44.9)$ & $119(55.1)$ \\
\hline \multirow{2}{*}{ Employed } & $65(10.3)$ & $566(89.7)$ & 197 (31.2) & $434(68.8)$ \\
\hline & \multicolumn{2}{|c|}{$\chi^{2}=10.006 ; p=0.002^{*}$} & \multicolumn{2}{|c|}{$\chi^{2}=13.302 ; p=0.001^{*}$} \\
\hline \multicolumn{5}{|l|}{ DDS category } \\
\hline Low & $93(23.8)$ & 297 (76.2) & $291(74.6)$ & $99(25.4)$ \\
\hline \multirow[t]{2}{*}{ Normal } & $12(2.6)$ & 445 (97.4) & $3(0.7)$ & 454 (99.3) \\
\hline & \multicolumn{2}{|c|}{$\chi^{2}=87.252 ; p=0.001 *$} & \multicolumn{2}{|c|}{$\chi^{2}=507.894 ; p=0.001 *$} \\
\hline \multicolumn{5}{|l|}{ Height-for-age Z-score (HAZ) } \\
\hline Stunted & $80(24.0)$ & $254(76.0)$ & $244(73.1)$ & $90(26.9)$ \\
\hline \multirow[t]{2}{*}{ Normal } & $25 \quad(4.9)$ & 488 (95.1) & $50(9.7)$ & $463(90.3)$ \\
\hline & \multicolumn{2}{|c|}{$\chi^{2}=67.804 ; p=0.001 *$} & \multicolumn{2}{|c|}{$\chi^{2}=357.752 ; p=0.001^{*}$} \\
\hline BMI-for-age Z-score (BAZ) & & & & \\
\hline Overweight & $1 \quad(2.0)$ & $50(98.0)$ & $5 \quad(9.8)$ & $46 \quad(90.2)$ \\
\hline Normal & $104(13.1)$ & 692 (86.9) & $289(36.3)$ & $507(63.7)$ \\
\hline & $\chi^{2}=5.442$ & & $\chi^{2}=14.855$ & $0.001 *$ \\
\hline $\begin{array}{l}\text { Weight-for-age } \\
\text { Z-score }(\text { WAZ) }\end{array}$ & & & & \\
\hline Underweight & $39(24.1)$ & $123(75.9)$ & $120(74.1)$ & $42 \quad(25.9)$ \\
\hline Normal & $38(7.0)$ & 504 (93.0) & $130(24.0)$ & $412(76.0)$ \\
\hline & $\chi^{2}=37.277$ & & $\chi^{2}=136.638$ & $=0.001 *$ \\
\hline
\end{tabular}

among primary school children. This therefore highlights the need to urgently institute measures to forestall this problem through the collaborative efforts of educational stakeholders, government and non-governmental organizations. The finding of at least half of the pupils having average academic performance in Mathematics and English language in present study contrasts with the results of the 2013 monitoring learning achievement numeracy test41 conducted in 2013 in Rivers State where more than half of the pupils performed poorly. Regarding the relationship between dietary diversity and academic performance, this study revealed an association between dietary diversity and academic performance in English language and Mathematics; such that pupils with low dietary diversity were more likely to have poor academic performance compared with pupils who had an adequate variety of diets. This is similar to observations made by Ogunlise $^{42}$ in Ekiti State of Nigeria, Abudayya et al in Gaza, ${ }^{43}$ and Florence et al in Canada. ${ }^{44}$ These researchers observed that the quality of food including dietary diversity, which implies nutrient adequacy, 
Table 5: Multivariate analysis of factors associated with academic performance in English and Mathematics

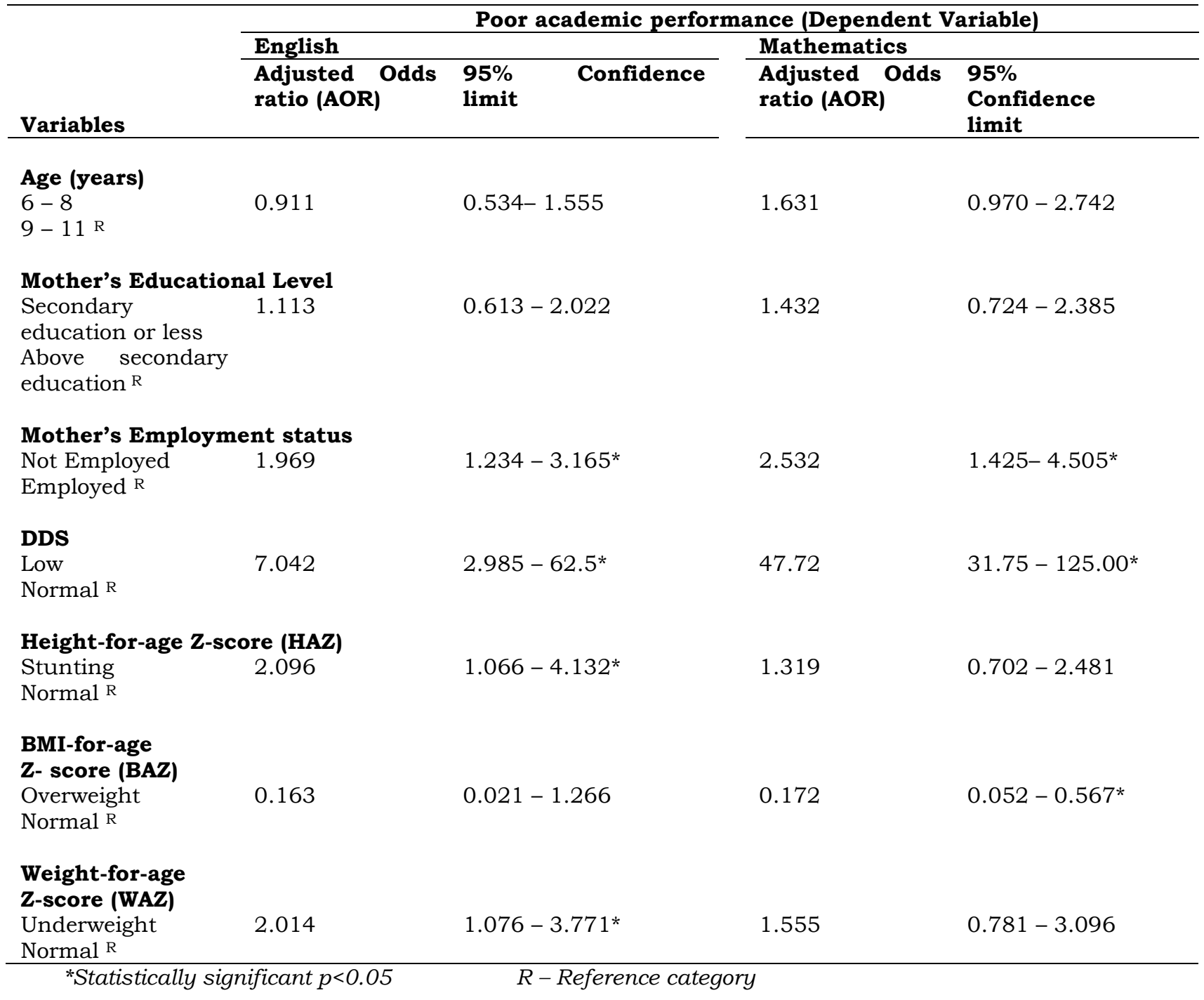

was significantly associated with academic performance.

Stunting was significantly associated with academic performance in English language but not with Mathematics in the index study, which is in keeping with the observations made by Hamid et al ${ }^{45}$ in Malaysia who identified a significant relationship between stunting and English language and thus suggested that chronic nutritional deficits may affect the cognitive performance of pupils. However, Ijarotimi et a ${ }^{46}$ in their research observed no significant difference in the educational performance of pupils who were stunted and those who were not stunted. Nonetheless, the index study implies that if the height-for-age status of pupils is improved, there might be a better academic performance in English language. Noteworthy, BMI-for-age was significantly associated with academic performance in Mathematics only among pupils in this study and overweight pupils were less likely to have poor academic performance in Mathematics as compared to pupils who were not overweight. This is in line with the observations made by Zaini ${ }^{47}$ in Malaysia who identified that overweight 
pupils performed better in Mathematics compared to underweight pupils. Results of this study also show that the overweight pupils performed better in English language and Mathematics compared to pupils who were not overweight. It may be that the overweight pupils have adequate nutrient required for proper cognitive function, hence their ability to perform better academically, though this may be influenced by other confounding factors. In contrast to the index study, observations by Acham et al in Uganda, ${ }^{48}$ researchers in the United States ${ }^{49-51}$ and Kolawole et al ${ }^{52}$ in Nigeria noted that being overweight was associated with poor academic performance. This may be as a result of poor concentration in class due to the stigma challenge they encounter from other pupils and health problems such as sleep apnoea, asthma, etc. as identified by some researchers. ${ }^{53-58}$

The strength of this study lies in its linkage of dietary diversity and nutritional status with academic performance among pupils in public primary schools. It provides evidence-based information for the institution of relevant public health policies and strategies targeted at promoting optimal nutrition and academic performance among primary school pupils in Rivers State, Nigeria. A limitation of the study is the cross-sectional study design used, thus associations could only be made and causal inference could not be established.

Conclusion: Poor dietary diversity and malnutrition were prevalent among public primary school pupils and these have a relationship with academic performance. The double burden of malnutrition (undernutrition and over-nutrition) observed among school-age children in this study area poses a significant public health concern. Therefore, there is a herald call to address the problems of malnutrition and poor dietary diversity among the country's future leader in a bid to not only promote their physical growth but their intellectual capabilities.

Conflict of interest: The authors declare no conflict of interest.

Acknowledgement: The authors are thankful to the Rivers State Ministry of Education for the permission granted to conduct this study in public primary schools in Port Harcourt Metropolis. We thank all teachers in the selected schools who assisted with coordinating the pupils during the data collection days to avoid interruption of school activities.

\section{REFERENCES}

1. Solomon D, Aderaw Z, Tegegne TK. Minimum dietary diversity and associated factors among children aged 6-23 months in Addis Ababa, Ethiopia. Int $\mathrm{J}$ Equity Health. 2017 Oct 12 ; 16(1):181. DOI: $10.1186 / \mathrm{s} 12939$ 017-0680-1. PMID: 29025434; PMCID: PMC5639776.

2. Ruel MT. Operationalizing dietary diversity: a review of measurement issues and research priorities. J Nutr. 2003; 133(11 Suppl 2):3911S-3926S. DOI:10.1093/jn/133.11.3911S.

3. Burchi F, Fanzo J, Frison E. The role of food and nutrition system approaches in tackling 
hidden hunger. Int $\mathrm{J}$ Environ Res Public Health. 2011; 8(2):358-373.

4. Rathnayake KM, Madushani PA, Silva KD. Use of dietary diversity score as a proxy indicator of nutrient adequacy of rural elderly people in Sri Lanka. BMC Research Notes. 2012; 5(1): 469.

5. Allen L, Dary O, de Benoist B, Hurrel R. (Editors). WHO guidelines on food fortification with micronutrients. Geneva, Switzerland: WHO; 2006. [Accessed 08/10/19.] Available at: http://www.who.int/nutrition/publications /guide_food_fortification_micronutrients.pdf

6. Singh Z, Chaturvedi R, Gupta E. Nutrient adequacy of school-going children can be determined by dietary diversity scores within different food groups. Int $\mathrm{J}$ Interdiscip Multidiscip Stud. 2016; 3(4): 74-79.

7. World Health Organization. Nutrition. [Accessed 10/05/19] Available from: http://www.who.int/topics/nutrition/en/.

8. United Nations Children's Fund. Nutrition. . [Accessed 10/05/19] Available from: http://www.unicef.org/nutrition/.

9. United Nations Children's Fund. Progress for Children: A report card on nutrition. 2006. [Accessed 10/06/19] Available from: http://www.unicef.org/progressforchildren /2006n4/files/PFC4_EN_8X11.pdf.

10. Ngo J, Ortiz-Andrellucchi A, Serra-Majem L. Malnutrition: concept, classification and magnitude. In: Caballero, B, Finglas, $\mathrm{P}$, Toldrá, F. (eds.). The Encyclopedia of Food and Health. 2016; 3: 610-630.

11. Gaurav K, Poudel IS, Bhattarai S, Pradhan PM, Pokharel PK. Malnutrition status among under-5 children in a hill community of Nepal. Kathmandu Univ Med J. 2015; 12(4): 264-268.

12. Aliyu AA, Oguntunde OO, Dahiru T, Raji T. Prevalence and determinants of malnutrition among pre-school children in Northern Nigeria. Pakistan J Nutr, 2012; 11(11): 10921095.
13. Manyike PC, Chinawa JM, Ubesie A, Obu HA, Odetunde O, Chinawa AT. Prevalence of malnutrition among pre-school children in south-east Nigeria. Ital J Paediatr, 2014; 40: 75.

14. Sawaya SM. Malnutrition and poor academic performance: critical contributions. Estudos Avancados, 2006; 20: 133-146.

15. You D, Jones G, Wardlaw T. Levels and trends in child mortality. UNICEF, 2011. . [Accessed 13/06/19] Available at: http://www.unicef.org/media/files/Child_ Mortality_Report_2011_Final.pdf.

16. Ara R, Huque SR, Adhikary M, Uddi MN, Mahmood AR, Ferdousi SK. Nutritional status among primary school children in a selected rural community. J Dhaka Med Coll. 2011; 20: 97-101.

17. The save the children fund. A life free from hunger. Tackling child malnutrition, 2012. . [Accessed 12/06/19] Available at: http://www.savethechildren.org.uk/sites/d efault/files/images/A_Life_Free_From_Hung er.pdf.

18. World Bank, IBRD. Food prices, nutrition, and the millennium development goals. World Bank, Washington DC. Global Monitoring Report, 2012. . [Accessed 12/06/19] Available from: http://www.imf.org/external/pubs/ft/gmr/ 2012/eng/gmr.pdf.

19. Best C, Neufingerl N, Van Geel L, van den Briel T, Osendarp S. The nutritional status of school-aged children: why should we care? Food Nutr Bull. 2010; 31(3): 400-417.

20. Nowsin I, Begum N, Akbar EB, Alam MM. Study on nutritional status of rural school children of Bangladesh. Bangladesh J. Physiol. Pharmacol., 2014; 30(1): 6-10.

21. Ochola S, Masibo PK. dietary intake of school children and adolescents in developing countries. Ann Nutr Metab., 2014; 64(2): 2440.

22. Rivers State Ministry of Education. School census analysis. Rivers State Ministry of Education Nigeria, 2012. 
23. Araoye M A. Research methodology with statistics for health and social sciences, 1st ed. Illorin, Nathadex Publishers 2004; 121 122 .

24. Agbo HA, Envuladu EA, Zoakah AI. A comparative assessment of the epidemiology of malnutrition among pupils in public and private primary school in Jos North Local Government Area of Plateau State, Jos. Journal of Medicine, 2012; 6(2); 34-38.

25. Food and Agriculture Organization. Guidelines for measuring household and individual dietary diversity. Food and Agricultural Organization Rome, Italy, 2011.

26. Kiboi W, Kimiywe J, Chege P. Determinants of dietary diversity among pregnant women in Laikipia County, Kenya: a cross-sectional study. BMC Nutrition. 2017 Dec; 3(1):12.

27. World Health Organization. Growth reference for 5-19 years. . [Accessed 17/07/19] Available from: http://www.who.int/growthref/en/.

28. Owusu SJ. Assessment of dietary intakes and nutritional status of school-age children participating in school feeding programmes at Otinibi and Danfa. [Dissertation on the Internet] Ghana: University of Ghana; 2013. [Accessed 13/06/19] Available from: http://ugspace.ug.edu.gh/.

29. Olumakaiye MF. Dietary diversity as a correlate of under-nutrition among school age. Ann Nutr Metab., 2013; 63: 569-569.

30. Swaminathan S, Thomas T, Kurpad AV, Vaz M. Dietary patterns in urban school children in south India. Indian Paediatrics, 2007; 44(8): 593-596.

31. Girma M, Stoecker B, Loha E, Bogale A, Abebe Y, Hambidge M. Consumption of micronutrient-rich animal source foods and cognitive performance in primary school children in Hawassa town, Southern Ethiopia. European Journal of Nutrition and Food Safety, 2015; 5(5): 1192-1193.

32. Senbanjo IO, Oshikoya KA, Odusanya OO, Njokanma OF. Prevalence of and risk factors for stunting among school children and adolescents in Abeokuta, Southwest Nigeria. J Health Popul Nutr. 2011; 29: 364-370.

33. Oninla SO, Owa JA, Onayade AA, Taiwo O. Comparative study of nutritional status of urban and rural Nigerian school children. J Trop Pediatr. 2007; 53(1): 39-43.

34. Mukudi E. Nutrition status, education participation and school achievement among Kenyan middle-school children. Nutrition. 2003; 19(7-8): 612-616.

35. Chowdhury SD, Chakraborty T, Ghosh T. Prevalence of under-nutrition in Santal children of Puruliya district, West Bengal. Indian Pediatr. 2008; 45(1): 43-46.

36. Mekonnen H, Tadesse T, Kisi T. Malnutrition and its Correlates among Rural Primary School Children of Fogera District, Northwest Ethiopia. J Nutr Disorders Ther. 2013; S12: 002

37. Srivastava A, Mahmood SE, Srivastava PM, Shrotriya VP, Kumar B. Nutritional status of school-age children: A scenario of urban slums in India. Archives of Public Health, 2012; 70(1): 1-8.

38. Adegun JA, Ajayi-Vincent OB, Alebiosu EO. Differences in the nutritional status of young school children from public and private owned primary schools in Ekiti State, Nigeria. Eur Sci J. 2013; 9(7): 1857-1881.

39. Olanipekun OT, Obatolu AV, Fasoyiro BS, Ogunba OB. Assessment of nutritional status of primary school children in Ibadan, South-West Nigeria. Nutr Food Sci. 2012; 42(6): 390-396.

40. Olatona FA, Adewale AE, Sekoni OO, Goodman OO, Nnoaham KE. Anthropometrically determined nutritional status of children in public and private primary schools in Lagos, Nigeria. Highland Med Res J, 2013; 13(2): 76-80.

41. Arbitrage Consult Limited. Monitoring learning achievement in Rivers State: A preliminary survey, Abuja 2013.

42. Ogunsile SE. The effect of dietary pattern and body mass index on the academic performance of in-school adolescents. 
International Education Studies, 2012; 5(6): 65-72.

43. Abudayya A, Shi Z, Abed Y, Holmboe-Ottesen G. Diet, nutritional status and school performance among adolescents in Gaza Strip. East Mediterr Health J, 2011; 17(3): 218-225.

44. Florence MD, Asbridge M, Veugelers PJ. Diet quality and academic performance. J Sch Health, 2008; 78: 209-215.

45. Hamid JMT, Mitra AK, Hasmiza H, Pim CD, Lor NG, Wan Manan WM. Effect of gender and nutritional status on academic achievement and cognitive function among primary school children in a rural district in Malaysia. Malays J Nutr, 2011; 17(2): 190200.

46. Ijarotimi OS, Ijadunola KT. Nutritional status and intelligence quotient of primary school children in Akure community of Ondo State, Nigeria. Tanzan J Health Res., 2007; 9(2): 69-76.

47. Zaini MZ. Effects of nutritional status on academic performance of Malaysian primary school children. Asia Pac J Public Health, 2005; 17(2): 81-87.

48. Acham H, Kikafunda JK, Oluka S, Malde MK, Tylleskar T. Height, weight, body mass index and learning achievement in Kumi district, East of Uganda. Sci Res Essay, 2008; 3(1): 1Á8.

49. Johnston CA, Moreno JP, Chen T, Stansberry SA, Woehler D. Impact of paediatric obesity on grades in elementary school. J Appl Res Child Risk, 2014; 5(1): 130.

50. Panfil Taylor. Associations between physical activity and weight status with grade school performance. MSc (Dissertation). Illinois State University, Illinois. 2015. [Accessed 17/06/19] Available from: http://ir.library.illinoisstate.edu/cgi.
51. Gable S, Britt-Rankin J, Krull JL. Ecological predictors and developmental outcomes of persistent childhood overweight; Washington, DC: United States Department of Agriculture, 2008.

52. Kolawole EB, Udeh DO. Predictive validity of body parameters on academic performance of Nigerian primary school pupils in Mathematics scholastic aptitude test. Pri.Res.Edu 2012; 2(1): 163-168.

53. Kristjansson AL, Sigfusdottir ID, Allegrante JP. Health behaviour and academic achievement among adolescents: The relative contribution of dietary habits, physical activity, body mass index, and self-esteem. Health Educ Behav., 2010; 37(1): 51-64.

54. Sahoo K, Sahoo B, Choudhury AK, Sofi NY, Kumar R, Bhadoria AS. Childhood obesity: causes and consequences. J Family Med Prim Care. 2015; 4(2):187-192.

55. Ding W, Lehrer SF, Rosenquist JN, AudrainMcGovern J. The impact of poor health on academic performance: New evidence using genetic markers. J Health Econ., 2009; 28(3): 578-597.

56. Landreth H, Malow BA, Shoemaker AH. Increased prevalence of sleep apnea in children with pseudohypoparathyroidism type 1a. Horm Res Paediatr. 2015; 84(1): 15.

57. Grandone A, Marzuillo P, Perrone L, del Giudice EM. Iron metabolism dysregulation and cognitive dysfunction in pediatric obesity: Is there a connection? Nutrients. 2015; 7(11): 9163-9170.

58. Zavodny M. Does weight affect children's test scores and teacher assessments differently? Econ Edu Rev, 2013; 34: 135-145. 